\title{
Drivers for IWMS implementation in real estate management
}

\author{
Maslesa, Esmir; Jensen, Per Anker
}

Published in:

Journal of Corporate Real Estate

Link to article, DOI:

10.1108/JCRE-08-2018-0025

Publication date:

2019

Document Version

Peer reviewed version

Link back to DTU Orbit

Citation (APA):

Maslesa, E., \& Jensen, P. A. (2019). Drivers for IWMS implementation in real estate management. Journal of Corporate Real Estate, 21(1), 72-87. https://doi.org/10.1108/JCRE-08-2018-0025

\section{General rights}

Copyright and moral rights for the publications made accessible in the public portal are retained by the authors and/or other copyright owners and it is a condition of accessing publications that users recognise and abide by the legal requirements associated with these rights.

- Users may download and print one copy of any publication from the public portal for the purpose of private study or research.

- You may not further distribute the material or use it for any profit-making activity or commercial gain

- You may freely distribute the URL identifying the publication in the public portal

If you believe that this document breaches copyright please contact us providing details, and we will remove access to the work immediately and investigate your claim. 


\title{
Drivers for IWMS implementation in real estate management
}

\author{
Esmir Maslesa and Per Anker Jensen \\ DTU Management Engineering, Technical University of Denmark, \\ Kongens Lyngby, Denmark
}

\begin{abstract}
Purpose: IT platforms like Integrated Workplace Management System (IWMS) gain higher importance in real estate management, but there is lack of knowledge on what IWMS is and what the drivers are for its implementation in real estate organisations. The article aims to provide knowledge on this.

Design/methodology/approach: The research combines theories of real estate management, IT implementations and change management with a qualitative case study of IWMS implementation in a public real estate organisation in Denmark. The research data consists of customer surveys, document studies, semi-structured interviews and in-depth analysis of IWMS features.

Findings: The article identifies several drivers for IWMS implementation such as data standardisation, validation and easier data exchange, business process optimisation, decrease in ITcosts, and improved customer service. Furthermore, the case study reveals that the IWMS implementation is not considered as a definite IT project, but as an organisational change project impacting the entire organisation.

Originality/value: There has so far not been any public real estate organisations in Denmark using IWMS and the knowledge about IWMS in public real estate sector is therefore limited. To date, no one has analysed what the drivers are for IWMS implementation in real estate organisations. This research paper brings new knowledge on IWMS and presents drivers for IWMS implementation observed from an implementation process in a public real estate organisation.
\end{abstract}

\section{Keywords}

IWMS, Integrated Workplace Management System, Real estate management, IT implementation, IT system, Organisational change

Article Type: Research paper

\section{To cite this document:}

Esmir Maslesa, Per Anker Jensen, (2019) "Drivers for IWMS implementation in real estate management", Journal of Corporate Real Estate, 21(1), 72-87. https://doi.org/10.1108/JCRE-08-20180025 


\section{Introduction}

In real estate management and facilities management, IT software systems can be divided in Data Containers (e.g. FTP servers, databases and BIM) and Workflow Systems (e.g. ERP, IWMS, CMMS and CAFM) (Ebbesen and Bonke, 2014). This paper focuses on workflow system Integrated Workplace Management System (IWMS).

Ebbesen (2015) identified 32 academic articles focusing on IT in facilities management and found that only 7 of them address workflow systems. However, none of the 7 articles on workflow systems focus on IWMS: five articles consider CAFM (Computer Aided Facilities Management) and two CMMS (Computerized Maintenance Management System), indicating a general lack of research on workflow systems, and particularly on IWMS. Furthermore, Ebbesen (2015) also found that only $25 \%$ of the articles focus on implementation and use of IT in organisations, while $75 \%$ focus on conceptualization and development. These findings highlight the overall need for further research on implementation and use of IT systems in real estate and facilities management.

At this time, there are no public real estate organisations in Denmark using IWMS and the knowledge about IWMS is therefore generally limited. However, the Danish Building and Property Agency (BYGST), who manages $4.000 .000 \mathrm{~m}^{2}$ of governmental buildings, and is the largest public real estate organisation in Denmark, is currently in the process of implementing IWMS, making it the pioneer in the field. This development therefore raises the vital research questions of, what is IWMS, and what are the drivers for its implementation in a large, public real estate organisation?

By studying the case of implementation of IWMS in BYGST and answering the research questions, this article aims to add knowledge on IWMS and the drivers for its implementation in real estate organisations.

In 2004, the American research and advisory company Gartner invented the term "Integrated Workplace Management System" and defined it as an enterprise suite that includes five key components: capital project management, real estate/property portfolio management and lease administration, space and facilities management, maintenance management, and sustainability/ facility optimisation and compliance (Schafer, 2014). A more recent definition describes IWMS as a software platform that enables leaders to manage the whole life cycle of their facilities, helps optimize the use of workplace resources and assists in cost containment by monitoring the real estate portfolio (Gartner, 2017). The IWMS is based on a single database platform through which multiple business processes are interconnected. This ensures easier management of information and increased interoperability since the core data comes from the common database, as illustrated in Figure 1.

In the European context, IWMS comes very close to the understanding of CAFM (Madritsch and May, 2009). However, the major difference is that CAFM mainly focuses on facilities management, space management and maintenance management while IWMS includes additional features like real estate and lease management, project management and environmental sustainability. 


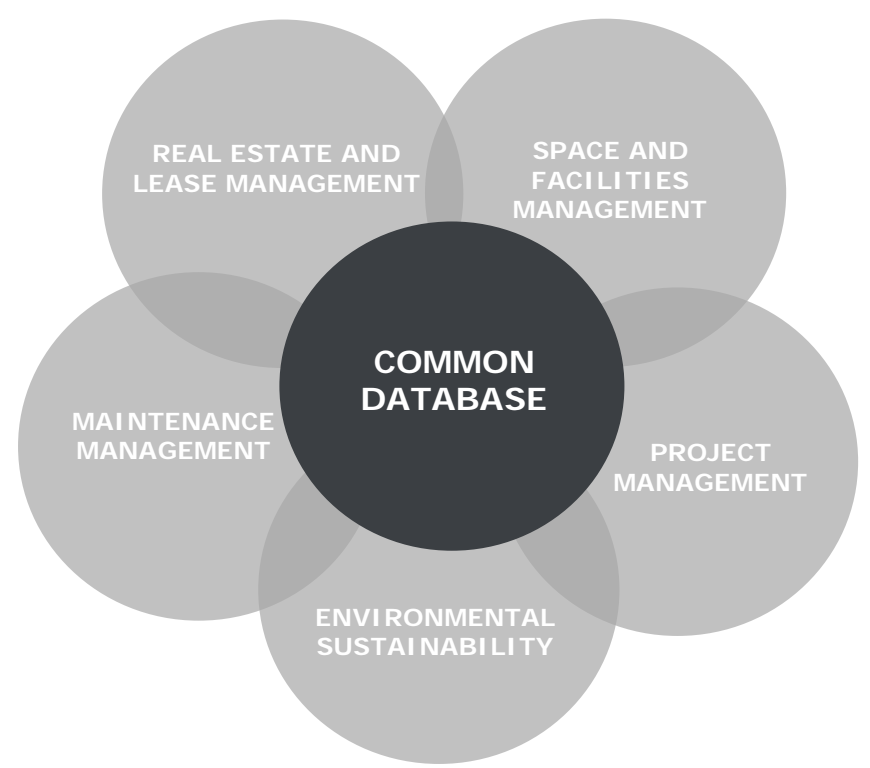

Figure 1: Generic model of Integrated Workplace Management System (IWMS)

Gartner has identified 14 global IWMS vendors, with the majority of them being present in North America and Western Europe (Gartner, 2017). In Denmark, there are at least 13 IT systems available for real estate and facilities management, of which 4 are categorised as IWMS (DFM Network and Basico, 2017). In Danish context, IWMS is considered as the most complex IT system that basically includes all functionalities from CMMS and CAFM, but also modules for financial management, portfolio management, space management and surveys. Some Danish IT providers describe their IWMS products as ERP (Enterprise Resource Planning) solutions, which also highlights the complexity of IWMS solution (DFM Network and Basico, 2017).

\section{Method}

The methodological approach is based on a qualitative case study of IWMS implementation in a public real estate organisation (Yin, 2014). The Danish Building and Property Agency (BYGST) was selected as a case since the agency was the first public real estate organisation in Denmark to introduce IWMS. The first author is industrial $\mathrm{PhD}$ candidate affiliated to the IWMS provider to BYGST and has as such achieved access to the research data presented in the article.

The research data consist of customer surveys, document studies and interviews. Customer surveys are conducted by BYGST and relate to tenants' satisfaction with BYGST's business areas in the period 2014-2017. The research is further supported by document studies of project initiation documents and system design documents.

For deeper analysis of drivers for IWMS implementation, five interviews with BYGST's representatives have been conducted in period May-October 2017. All interviews were conducted by following the same interview template prepared before the interview sessions. The interviews were originally conducted in Danish and were later translated to English by the authors. The interview template included several questions on topics like interviewees' background and BYGST's 
organisation and real estate management tasks, IT system landscape before IWMS, BYGST's data needs, drivers for IWMS implementation and the implementation process. All interviews have been recorded, transcribed, validated by the interviewees, and in the end analysed by cross comparing the answers on each interview topic. The purpose of the interviews was to gain deeper knowledge on why BYGST has decided to implement IWMS, and which benefits the organisation expected to realise by implementing such a system. The interviews were partly semi-structured and partly structured. Each interviewee was asked open and closed questions concerning the relationship between real estate management and the IT system landscape in BYGST before IWMS implementation. In the open questions, interviewees were asked to describe BYGST's organisation and business processes, and to give their personal view on the IT systems and related challenges before IWMS implementation, as well as their expectations for IWMS. In the closed questions, each interviewee was asked to evaluate specific topics regarding IT systems with grades 1-10, with 1 being low, and 10 high satisfaction. Some of the closed questions were: "What is your evaluation of user satisfaction with current IT systems?" and "How satisfied are you with the data exchange processes between departments through current IT systems?”

The interviewees and their profiles are presented in section 4.3. Their evaluations and citations in combination with BYGST's customer surveys and document studies represent the research data used for answering the research question regarding the drivers for IWMS implementation.

In the following, the paper presents theoretical relationship between real estate management and IWMS in section 3. After theoretical framework, the case study and research data are introduced in section 4, while findings are presented in section 5. Discussion of the findings is in section 6, and conclusions are drawn in section 7.

\section{Theory}

\subsection{Real estate management}

Real Estate Management (REM) is very dependent of the context, where it takes place. In a commercial setting with a focus on real estate investments in property for renting out and/or selling, the aim is to get the best possible return on investment in the short and long run (van der Voordt; 2017). This is not in focus in this article.

The situation is very different, when REM concerns the real estate to be used by an organisation. This is commonly called Corporate Real Estate Management (CREM). CREM focuses on alignment of real estate to corporate needs and objectives, incorporating the needs and wishes of shareholders and different stakeholders on strategic, tactical and operational levels (van der Voordt, 2017). Dewulf et al. (2000) define CREM as “the management of a corporations' real estate portfolio by aligning the portfolio and services to the needs of the core business (processes), in order to obtain maximum added value for the business and to contribute optimally to the overall performance of the corporation" (Dewulf et al., 2000).

Concerning public real estate, i.e. real estate owned or rented by ministries, municipalities and other governmental agencies, the term Public Real Estate Management (PREM) is sometimes used as a parallel to CREM in private corporations. A Dutch PhD-thesis from 2002 concerning PREM noticed 
a shift was going on from decentralised real estate management with a focus on facilitating primary processes towards integration of FM and CREM in centralised shared services (van der Schaaf, 2002).

CREM is both as an academic discipline and a profession in practice closely related to Facilities Management (FM). Van der Voordt (2017) has made a comparison of CREM and FM. According to this, CREM has its foundation in asset management, facility management and cost control and its alignment to general management, while FM is characterised by its focus on non-core business services, workplaces and their management. Another difference is that CREM has its focus on real estate as physical and economical assets utilized by an organisation, while FM has a wider service focus, including demands related to space and infrastructure as well as people and organisations (van der Voordt, 2017). There is a trend towards CREM and FM becoming more integrated and converging, which for instance is expressed by the publication of a recent book concerning FM and CREM as value drivers (Jensen and van der Voordt, 2017).

In this article, we mainly use the term real estate management understood as management of public real estate by a state agency, who owns and lets out real estates to other public organisations. This has been the main responsibility for the case organisation BYGST. However, in 2017 BYGST also got the responsibility to procure and provide facilities services to the public user organisations, who rent space from BYGST. Therefore, in the future BYGST will become responsible for both PREM and FM.

\subsection{IWMS in real estate sector}

Each real estate includes physical systems like heating, lighting, plumbing and ventilation. The same real estate also includes human systems (how occupants use the space) and assets and equipment that people need to perform their jobs. All these systems interact with each other and must be integrated. Therefore, there is a need for data on how each system is working in relation to others (Short, 2017). Having access to facts and figures is not enough. The IT systems must provide deeper insight on the data presented on the users' computer screens. The data analyses must be easy to understand, visually stimulating, accurate and convincing (Sandquist, 2015). This is where an IWMS shows its value, since the system allows integration of relevant business processes.

Hanley and Brake (2016) consider IWMS as a technology solution that can help organisations to record, measure, manage and optimise assets (built assets, fixed assets, mobile assets, asset systems and people) and their complex inter-relationships, which are only becoming more complex in the advent of the Internet of Things (IoT) and Big Data.

IWMS operates with relational datasets meaning that a work task is linked to data records for the associated employee, assets, and procedures. The first step, when implementing IWMS, therefore is to link the organisational records with resources such as people, locations (site, property, building, lease unit), assets, geographical and organisational hierarchies, and cost codes. A strategic and structured approach is required when implementing an IWMS (Hanley and Brake, 2016). The criteria for successful implementation seem to be planning, expectation setting and managing the change within the organisation (Gibler et al., 2010). A phased implementation is considered the most efficient approach. The clients should start with whichever application that delivers the most immediate value 
to the organisation. Depending on the system configuration, IWMS can provide functionality to support best practice management of business processes relating to workflow management, project management, lease management, environmental reporting and asset management.

A key benefit of an IWMS is that it uses the same underlying data set, whether it concerns assigning a maintenance work task, scheduling a project, or disposing of an asset (Hanley and Brake, 2016). With the right information, the system can perform useful actions without human interaction and thereby save some labour costs, or, it can assign a task to an employee that can perform a certain task and prevent a costly failure, if something is wrong. When it comes to the process of capital planning from lifecycle and management of facilities perspective, IWMS can help buildings owners to understand, what projects need to be prioritized and funded (Short, 2017).

Because of its size, complexity and functionality features, IWMS is mainly recommended to real estate organisations that usually manage large portfolios (over $100.000 \mathrm{~m}^{2}$ ) across several locations. Real estate organisations with few properties might have better benefits from implementing CAFM or CMMS. Typical IWMS users are corporate real estate managers, facilities managers, maintenance managers and environmental/energy managers and their teams. Top management can use IWMS for strategic reporting on capital projects, maintenance tasks, space utilization or energy efficiency benchmarking.

Historically, the main driver for implementing an IWMS solution was cost management. Managing facilities expenses is still an important consideration, but providing a flexible workspace, where people want to work, has increased in importance. For example, a recent study conducted by Gartner shows that employees' work environment has a significant impact on their effectiveness and engagement, yet only 34\% of workers like their workspace (Gartner, 2017). Another aspect is that employees in the REM sector spend a lot of time in the field and need to be able to bring and complete their tasks remotely. IWMS supports these needs since the technology is available on different products (tablets, smartphones) and mobile apps.

There are several global companies that use IWMS. General Electric (GE) implemented an IWMS as part of a global restructure of its portfolio. The implementation supported significant cost savings and reduced operational costs. Nokia implemented an IWMS to manage its portfolio, which was previously managed in 65 different systems. The implementation reduced real estate portfolio of more than $278.700 \mathrm{~m}^{2}$ and operational costs by 500 million Euro, and reduced energy consumption by $7 \%$ (Hanley and Brake, 2016).

An UK government organisation managed real estates with siloed business processes through over 70 siloed systems. An IWMS implementation led the organisation to directly interface with commercial, financial and personnel systems. This has improved data quality, enabled better financial forecasting, introduced procurement savings, reduced maintenance costs and significantly reduced support costs of legacy systems (Hanley and Brake, 2016). One of the key lessons learned from this case was that the successful implementation was dependent on a pace of change that the organisation and its employee could support, particularly reflecting that business process and data governance needed a step change to evolve with the new technology. 
For larger real estate organisations, an IWMS brings much greater benefits than using several standalone applications. Hanley and Brake (2016) claim that organisations that have implemented an IWMS have experienced significant operational benefits, through more efficient business processes, better stakeholder relationships, reduced operating costs, improved productivity and clear demonstration of legal compliance. With a single data repository, transparent reference data, and comprehensive analytics, organisations can embrace a new generation of key performance indicators to command differential advantage in their competitive environments (Hanley and Brake, 2016).

\section{Case study and data collection}

\subsection{The Danish Building and Property Agency - Bygningsstyrelsen (BYGST)}

BYGST is the Danish state's property enterprise and developer, whose main task is to provide work spaces and office and research environments on market terms for its customers, including universities, central administration, police and the courts. BYGST was established in October 2011 as part of a Danish governmental formation. Several governmental agencies (part of the Agency for Palaces and Properties, University and Building Agency, Business and Construction Agency) have been consolidated into BYGST, and the agency is still undergoing organisational changes. BYGST solves its task by owning and renting out buildings of the state through new construction and modernisation, and by redistribution of private leases to the state institutions. The agency has about 300 employees that manage 1.800 leases covering more than 4 million $\mathrm{m}^{2}$ of building area. About 1,2 million $\mathrm{m}^{2}$ are private leases and public-private-partnerships, 2 million $\mathrm{m}^{2}$ are used by the universities, and approximately $800.000 \mathrm{~m}^{2}$ are office buildings owned by BYGST (Bygningsstyrelsen, 2017).

The current IT system landscape is diverse due to former reorganisations, different employee needs, working cultures and local IT-solutions emerged over many years prior to the consolidation. The IT system landscape is a product of long-term accumulation of silo-based systems that support individual needs of different departments at BYGST. Several IT systems contain the same type of data that is updated individually in each system, leading to missing coordination and poor data quality (Anonymous, 2018). BYGST therefore needs a more consolidated IT system landscape that can reduce the amount of IT systems and secure consistent, valid data across the entire organisation. For solving the problem, BYGST visited several real estate organisations using IWMS outside Denmark (The Dutch Building and Property Agency and 4 companies/municipalities in the UK). Based on the experiences and recommendations from a market survey, BYGST decided to introduce IWMS (Bygningsstyrelsen, 2015). The internal need analysis and the market survey was initiated in 2012. The tendering and contract sign-off took place in 2016. The implementing process (design-build-test) was initiated in early 2017 and runs till the end of 2018. The implementation involves four organisations: BYGST as a customer, an external consulting company engaged to support the implementation, the IWMS provider (national IT company selling the IWMS in Denmark on license), and the IWMS developer (multi-national IT company that has taken over the company, who has originally developed the IWMS). The official implementation team includes 35 people of which 14 are from BYGST, 12 from the external consulting company, 5 from the IWMS provider, and 4 from the developer. Moreover, there are additional personnel involved in the implementation as needed. 
BYGST has a vision of being the preferred property manager for customers and the state. The strategic goal is to build up a strong, data-driven knowledge organisation concerning work spaces and efficient building processes, construction and real estate management. A stronger, data-driven knowledge organisation is expected to create the basis for advising and decision-making that will result in cost effective solutions for the agency and their customers (Bygningsstyrelsen, 2012). By introducing IWMS, BYGST wants to combine data, knowledge and professional experience to change the organisational configuration and deliver improved customer service.

Recently, BYGST got responsibility for providing FM services to their tenants by outsourcing as mentioned in section 3.1, but this business area is still under development at BYGST and therefore not covered by this article.

\subsection{Customer surveys}

Every year BYGST conducts a survey on tenant satisfaction with core business tasks provided by BYGST. The survey is distributed to tenants across universities and state properties (private leases excluded) and measures general satisfaction with BYGST's portfolio management and six specific business areas provided by BYGST. The 2017 survey contained 515 responses. The grades ranged 15 , with 1 being lowest and 5 highest satisfaction. The tenant satisfaction within six specific business areas for period 2014-2017 is presented in Table 1.

\begin{tabular}{|l|r|r|r|r|}
\hline Business area & $\mathbf{2 0 1 4}$ & $\mathbf{2 0 1 5}$ & $\mathbf{2 0 1 6}$ & $\mathbf{2 0 1 7}$ \\
\hline Operation and Maintenance & 3.8 & 3.7 & 3.7 & 3.8 \\
\hline New construction, modernisation and reconstruction & 3.8 & 3.6 & 3.6 & 4.0 \\
\hline Moving & 3.7 & 3.5 & 3.6 & 4.4 \\
\hline Rent Collection & 3.7 & 3.5 & 3.7 & 3.6 \\
\hline Energy Consulting & 3.3 & 3.1 & 3.4 & 3.4 \\
\hline BYGST as developer (new) & - & - & - & 3.8 \\
\hline
\end{tabular}

Table 1: Tenant satisfaction with BYGST's business areas across universities and offices (excluding top managers).

The general tenant satisfaction with BYGST's real estate management was 3.6-3.7 in the period 20142017. Moreover, the table shows that, in 2017, the tenants were most satisfied with BYGST's service on moving projects and that tenants' satisfaction with BYGST's handling of new construction, modernisation and reconstruction projects has increased. On the other hand, the tenants were least satisfied with rent collecting and energy consulting services. Among all six business areas, tenant satisfaction has generally been the lowest with energy consulting services in the period 2014-2017.

\subsection{Interviews}

During the system implementation, five semi-structured interviews regarding drivers for IWMS implementation have been conducted. The interviewees were selected based on their function and business area at BYGST as shown in Table 2. 


\begin{tabular}{|l|c|l|c|c|}
\hline Function & $\begin{array}{l}\text { Years at } \\
\text { BYGST }\end{array}$ & Business area & $\begin{array}{l}\text { Interview } \\
\text { date }\end{array}$ & $\begin{array}{l}\text { Interview } \\
\text { duration }\end{array}$ \\
\hline IT senior consultant & 4 & $\begin{array}{l}\text { Project management, IT and business } \\
\text { strategy, change management }\end{array}$ & $19-05-2017$ & $01: 30: 49$ \\
\hline Technical consultant & 6 & Energy management & $06-06-2017$ & $00: 53: 34$ \\
\hline Head of IT dept. & 4 & IT systems and data & $16-08-2017$ & $00: 56: 56$ \\
\hline Head of Building dept. & 6 & Buildings, Construction & $18-08-2017$ & $01: 18: 43$ \\
\hline Head of Lease dept. & 6 & Lease management & $03-10-2017$ & $00: 53: 14$ \\
\hline
\end{tabular}

Table 2: A list of interviewees and details of each interview.

The IT senior consultant has background in computer science, finance and change management and is responsible for project management regarding IWMS implementation. The technical consultant has background in engineering and is responsible for energy management of BYGST's properties. The head of IT department is a Master of Business Administration and has been working with IT in public organisations for 30 years. He is responsible for IT systems and data at BYGST. The head of Building department is a Master of Public Management and is responsible for operation and maintenance of BYGST's properties. The head of Lease department is an economist responsible for lease management department at BYGST.

\section{Findings}

\subsection{IT system landscape at BYGST}

Each interviewee could evaluate eight specific topics on BYGST's IT system landscape before IWMS implementation with grades 1-10, with 1 being low, and 10 high satisfaction with the existing IT processes and solutions. The results of their evaluations are shown in Figure 2.

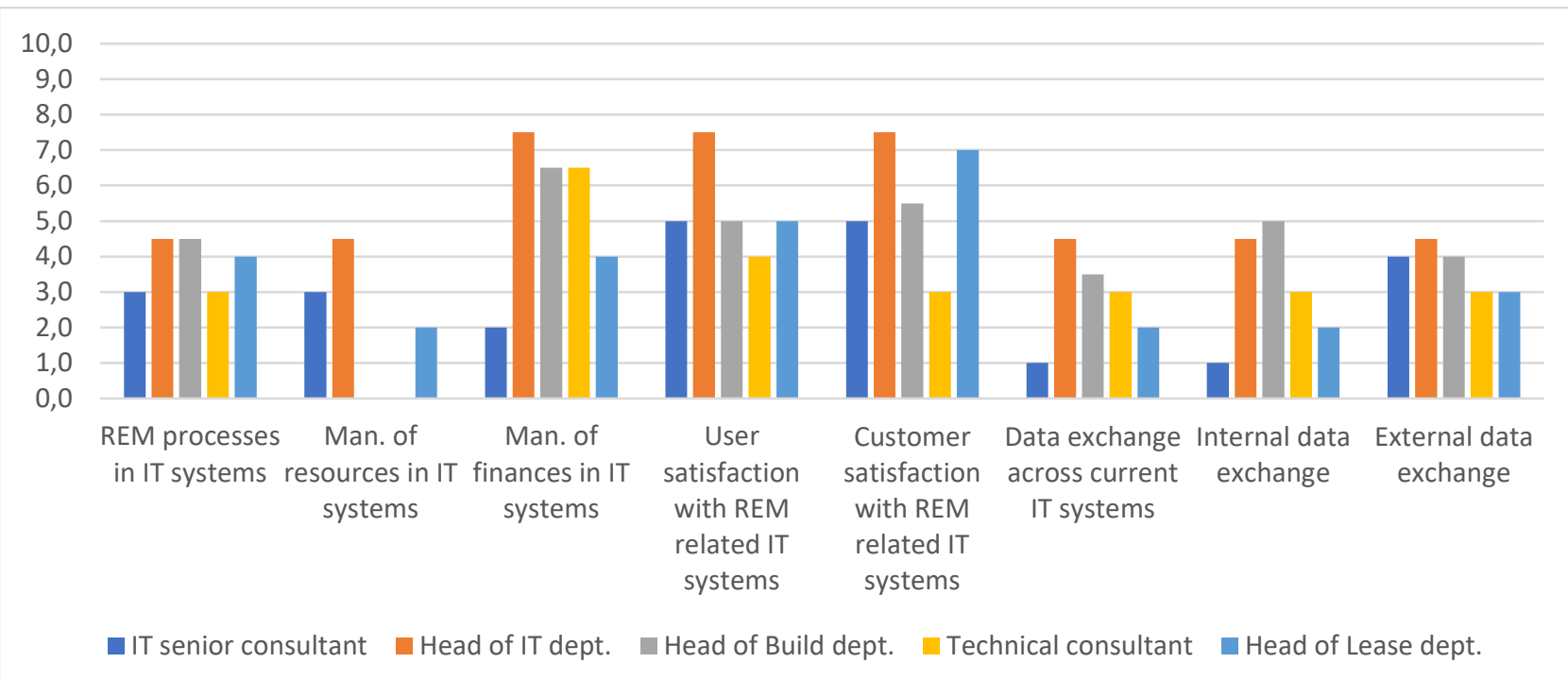

Figure 2: Evaluations of BYGST's IT system landscape before IWMS.

The interviews revealed several challenges related to the IT system landscape before IWMS implementation. Some of the biggest challenges were related to data exchange. When asked to describe the data exchange processes between IT systems before IWMS, the head of IT department explained: 
"Partly, we have redundant data, partly we have a maintenance work that is greater than it should be because they are redundant, and partly we have challenges in compiling the data across the organisation because the definitions in the individual systems are not necessarily the same."

Data exchange across existing IT systems obtained the lowest average score (2.8) because of the missing system integrations and use of different data formats. Furthermore, due to missing system integrations, internal data exchange processes obtained the second lowest average score (3.1) while data exchange processes with external users had the third lowest score (3.8). Consequently, BYGST faced challenges in managing processes and resources related to PREM since the data inconsistency made it difficult for the organisation to have a proper performance overview across entire real estate portfolio.

However, Figure 2 also shows that the interviewees at the same time evaluated user satisfaction (BYGST's employees) and customer satisfaction (e.g. tenants) with the current IT systems to be high relative to other topics with average score of 5.3 for the users and 5.6 for the customers. These findings contrast with previous findings regarding data exchange, and the head of Lease department tried to explain:

"I think they have learned to live with the systems. They may see the systems are not optimal, but you must get the best out of them. This is sometimes the case. Live with it."

Regarding the IT systems, all five interviewees estimated that BYGST used more than 10 different IT systems for supporting REM. The IT system landscape included FM systems (CAFM), standard IT systems like MS Office and Outlook, department-specific systems used for accounting, lease management, energy management, and some employees even used hand notes. When asked to describe challenges with current IT systems and drivers for IWMS implementation, the head of IT department explained:

"We have maybe 25 IT systems that exist separately, and they are also being maintained to some extent individually. Of course, it is always problematic to start compiling the data to create a foundation that goes across some disciplines. It is a big issue for us. That's why we want to put all these IT systems into IWMS, concentrate on one, common database so when we make decisions, they are on the same basis, with the same understanding of what these data are expressions of, and that we are actually sure that the same decision-making basis is present before and after."

The technical consultant also gave his view on BYGST's IT system landscape and reasons for implementing IWMS:

"We cannot keep on having 20,15, or how many IT systems there are now. There must be something as basis, just because there are so many factors going through - areas, customers, users - and it needs to be maintained. Unless we have one platform where we can have basic information, it's hard to make use of economies of scale and run things cross-sectionally. That is the reason why we need one common system. Also, to be able to maintain it."

According to the IT senior consultant, one of the benefits by implementing IWMS is that this system solution can provide synergies between different business areas in REM: 
"If you have better facilities management, combined with better lease management and other things, it will be easier to find out which properties you should phase out, which properties you should keep, and which synergies are coming out of that, instead of keeping most of it in Excel sheets so that much information is lost, because many decisions are not based on a professional basis, but on a more personal basis."

The above statements draw parallels between BYGST and an UK government organisation that earlier used over 70 siloed systems for REM. In an UK case, Hanley and Brake (2016) found that the IWMS implementation has improved data quality, reduced maintenance costs and significantly reduced support costs of legacy systems - some of the issues that the interviewees also expect IWMS can solve for BYGST.

\subsection{IWMS implementation process}

Regarding the implementation process, all interviewees agreed that the implementation of IWMS should be considered as an organisational change process rather than a definite IT project. For example, when asked to give his view on the IWMS implementation process, the IT senior consultant stated:

"I see it as a change management project. I have always done that. From day one, I have always said that it is a change management project. If we run this as an IT project, it will never be a success.”

Head of IT department gave a similar view on the implementation process:

"The IWMS (implementation) process at BYGST is NOT an IT project. It is an organizational change project that is tool-supported by technology. It is important to understand. Technology is the lever of the organizational change in which we change procedures, rules and contexts to make things more consistent than they are today."

Also, the technical consultant expressed his thoughts on the implementation process:

"An IT project is worth nothing unless you can get someone to manage it and follow your organisation. There are a lot of processes, workflows and conversions that have to be done internally to succeed."

Another important finding regarding the implementation process is the implementation period. The initial thoughts on IWMS implementation started to flourish at BYGST in 2012 while the actual implementation started in early 2017 and runs till the end of 2018. Regarding the implementation period, the head of Lease noted:

"I think I have heard about this system for almost three years, and it is first now that we are making design documents. That is where we are now, three years after. I do not know if it is normal that it takes so long, but I think it is a long process. One could say it is a long process for the employees to be in." 


\subsection{IWMS solution at BYGST}

BYGST has decided to implement five IWMS modules to their organisation: Core, Lease, Project, Customer Relationship Management (CRM), and Energy module. Table 3 provides brief overview of main functionalities of each module.

\begin{tabular}{|l|l|}
\hline IWMS module & Main functionality \\
\hline Core & $\begin{array}{l}\text { Delivering and maintaining data on properties, buildings, floors, rooms, units } \\
\text { Delivering and maintaining data on building owners, tenants, suppliers }\end{array}$ \\
\hline Lease & Managing lease contracts, rent processing, service charge processing, deposits, etc. \\
\hline Project & Documenting and managing construction, renovation and modernization projects \\
\hline CRM & Documenting and processing requests and questions from the customers/tenants \\
\hline Energy & $\begin{array}{l}\text { Energy management - electricity, heating and water consumption reporting } \\
\text { Energy dashboards }\end{array}$ \\
\hline
\end{tabular}

Table 3: IWMS modules and their functionality areas at BYGST.

Besides the five IWMS modules, the design solution also includes four integrations with other IT systems and databases. The integrations cover 2-way integrations with Energy Management System (EMS) and financial system, and 1-way integrations with central building database based on Objectoriented Input System (OIS) - OIS is the master, and an IWMS integration with project collaboration platform for construction industry.

In the following, a more detailed description of each IWMS module from Table 3 is given, as well as some drivers for their implementation.

\subsubsection{Core module}

The Core module manages data relating to properties, buildings and their users. The module is based on the OIS database delivering data on building owners and tenants, property/building number, address, area size of various types, cadastral area, year of construction etc.

The main requirements of the Core module are the ability to hold portfolio information on all building types, to store different types of records (buildings, floors, rentable units), to store records by key elements and be able to link elements together, e.g. link rooms to floors. Furthermore, the module is used for creating leases in order to generate rent/service charges and allow supplier records to be added for entering invoices. The Core module provides also ability to store related documentation, e.g. floor plans, energy information, building information so that all personnel can view all details (subject to security).

Securing valid core data about buildings and tenants was also in the IT senior consultant's focus, since BYGST has been struggling with data consistency and validity for a long time:

"Now, it is only about acquiring valid data. We are completely down there where we want valid data. Just getting valid data, it is a huge development. But it is not that far to the other things once data is in place." 
Additionally, the head of Building department specified the following issues with data relating to buildings and their users:

"I do not think it is easy (to share the data) with existing IT systems. It is on the economy side because we run the same system. But at the task level, it is hard to do. There, it is often that we need to extract some summaries to Excel sheets if they need the information."

These statements explain the importance of data in REM and highlight some of the issues regarding data management at BYGST. Furthermore, as pointed out by Sandquist (2015), the data analyses must be easy to understand, visually stimulating, accurate and convincing, which BYGST expects to achieve through IWMS implementation.

\subsubsection{Lease module}

The Lease module manages processes relating to tenants and lease administration. Tenant's cycle covers moving in and out phases and the period of actual lease agreement. Moving-in phase includes creation of a lease contract, first time charging and moving-in report and lease agreement. During lease period, administration processes regarding rent collection and notifications, regulation of deposit, regulation of lease area, consumption settlement and warnings of new rents, taxes and charges are handled in Lease module. When moving out, the module is used for registering lease termination, sending termination confirmation to the tenant, creating and sending moving-out report and move statement. According to the head of Lease department, IWMS can bring two benefits for lease management:

"There are two things I want from IWMS: I want that my department becomes more effective in their workflows, meaning that they use less resources so that they instead of doing things three times only do it once. And I also hope that the system will make it more flexible to help customers more, among others with forecasting. They ask about many things that they would like to have: e.g. budgets, but we cannot help them since it is a manual process and we have to use a lot of resources on that, but we don't have time. In that way I hope that we will be able to make our customers happier and be more flexible in relation to them."

\subsubsection{Project module}

As governmental real estate organisation, BYGST currently runs construction projects for almost 1.3 billion Euro. In relation to that, BYGST wants to hold information for major construction projects, tasks and associated costs in one place. Furthermore, the agency also wants full visibility of project documents for internal and external users.

The Project module in IWMS allows BYGST to record new construction projects, their milestones and documentation. Projects in IWMS are used to record when a request has moved out of the CRM cycle and passed to the project management team. IWMS can hold financial information against a project e.g. budgets, templates, etc. with full email authorisations and approval process.

The main goals for the Project module are to replace existing project tool for high level project portfolio management, reduce amount of project data for registration, add missing data that cannot be delivered by the existing project tool but is demanded by BYGST, and implement simple methods 
for registration of key project data (i.e. few reporting fields, as much automated data entry a possible, as few advanced or complex features as possible).

\subsubsection{CRM module}

The CRM module is used for processing and documenting all requests, questions, complaints etc. coming from the current or future tenants of the buildings in the BYGST's portfolio. This module is used for holding all relevant information and discussions regarding customer relationship management in one place.

During the implementation workshops, it was found that there is a significant number of cross-module functionalities related to the customer relationship management. The CRM module will therefore have dependencies on other IWMS modules that BYGST implements.

\subsubsection{Energy module (environmental sustainability)}

Prior to IWMS implementation, BYGST has been struggling with data validity on energy consumption, correct baseline estimation and performance benchmarking across property portfolio. All these issues are closely linked to the customer satisfaction surveys from section 4.2 in which energy consulting generally has had the lowest customer satisfaction over several years. For example, the tenants have especially been complaining about erroneous energy invoices and missing access to their consumption data. Some of the issues with poor energy management were also specified by the head of Building department:

"The (old IT) system was based on data loggers installed on the meters. There were many errors with them. The errors consisted of wrong installations, e.g. if data loggers did not match the meter, if the meter was set up to different factor, then incorrect numbers were reported. For example, it could also happen that the utility companies went out and changed the meters without informing us, and if we did not detect it, there were errors in data. So, our old IT system was challenged by the fact that there were many data holes in it."

For solving the issues with poor energy management and improving environmental sustainability of its portfolio, BYGST has decided to use the IWMS Energy module. However, during discovery phase for IWMS implementation, the IWMS module alone was considered not to be sufficient to fulfil all BYGST's requirements on environmental sustainability monitoring and reporting. The Energy module is therefore supported further by an Energy Management System (EMS) solution through an interface that can deliver deeper insight on energy performance. The EMS solution is a separate IT system delivered by the same provider as the IWMS.

Currently, the new energy management model is partly up and running through the EMS, but there is no full integration with the IWMS yet. The EMS as a stand-alone solution enables relevant stakeholders (energy managers, facilities managers and tenants) to access validated hourly-resolution data which enables to track changes and the effects of energy-saving measures or other interventions. The head of Building department expressed his opinion on the new model: 
"Today we measure directly on consumption meters (through EMS), and we collect data directly from the utility companies in most places. One can say it is settlement data, they cannot be wrong because it is the same data as you pay for."

On new energy management model and its benefits, the head of IT department stated:

"Now we have some values where we within few days can see whether it changes something that we turn up or down the radiator, instead of waiting for a month and maybe being able to interpret some result. Now we can see a direct causal relationship between an activity and effect. It gives us another opportunity, partly to energy optimize, but also to guide customers in the correct use of a building. But also to do damage control significantly faster, if suddenly something happens so the consumption peaks, because we get these hourly values. Previously, we got some data values with significantly longer intervals."

The entire design solution for new energy management model at BYGST and the benefits of EMS are further described in Anonymous (2018).

\section{Discussion}

Our study shows findings similar to earlier research on IWMS implementations (e.g. Hanley and Brake 2016), but it also indicates a potential difference in drivers between PREM and CREM organisations. For example, Hanley and Brake (2016) showed that global CREM organisations mainly implemented IWMS with focus on cost reductions. On the other hand, our study indicates that PREM organisations might have other reasons for implementing IWMS. The main drivers for implementing IWMS in this study can be classified as quality improvements of internal business processes. For example, BYGST has decided to implement five IWMS modules to support their organisational change process. The agency decided to move away from a silo-based organisation and build up a knowledge-based organisation in which the employees use the same core data for solving their tasks.

Based on the findings from interviews and document studies, several drivers for implementing IWMS at BYGST can be identified. Some of the main drivers relate to data standardisation, validation and easier data exchange across departments and with external users. Other drivers cover faster execution of business processes, time savings and resource optimisation, better interoperability between departments, and savings on IT costs.

BYGST has been using and maintaining the same data in various IT systems, which over the years led to data inconsistency and missing overview of the actual performance across building portfolio. Especially challenges with the building area data were observed. During the implementation, it was found that BYGST was using up to 15 different building area types (e.g. gross/net area, lease/contract area, heating area, drawing area, common areas etc.) which were mainly stored and updated in single point systems, without strategic coordination of data maintenance. When implemented, IWMS will be able to handle all these building area types in one place, ensuring that any changes in area data become immediately valid across the entire organisation. Moreover, IWMS will enable easier data exchange across departments since all employees will have access to relevant data through specific IWMS modules. As a PREM organisation, BYGST is interested in strategic reporting and benchmarking of its buildings on different KPI's, and this is where data exchange really shows its 
value. However, to be able to conduct strategic reporting and benchmarking, basic business processes and data types must be standardised so there is a clear understanding of how the output is achieved. Standardising the data and improving data exchange processes through IWMS implementation cannot happen without help. The implementation must happen in parallel with business process reengineering in which workflows related to data needs, data collection, handling and analysis are mapped, reviewed and adjusted accordingly. This approach justifies, why IWMS implementation is not perceived as a definite IT project by BYGST, but as the organisational change process.

Single point systems like CMMS or EMS have a high degree of customization for a specific need. They may be more specific to each department's concrete needs, but they also have limited crossfunctionality that is required by large REM organisations. Choosing IWMS may reduce possibility of fulfilling all department-specific needs, since all processes are aggregated in a single system. In this way, the possibility to individualise specific business processes becomes lower with an IWMS solution compared to the single point systems. On the other side, IWMS can be configured to match more strategic needs of an organisation. This is especially valuable for larger REM organisations that require certain level of standardisation across the entire organisation. Furthermore, since IWMS features many cross-functions, the system can be used to replace several single point systems, resulting in potential savings on IT costs. This situation was observed in energy management, in which the old data logger system was replaced by EMS and the upcoming IWMS interface. However, this particular design solution has also revealed certain limitations in IWMS. For example, the IWMS Energy module was not sufficient to cover all customer's needs on environmental sustainability reporting. The Energy module is therefore supported by a single point system, EMS, which delivers deeper insight on energy management of BYGST's properties.

The organisation of IWMS implementation at BYGST, as described in section 4.1, is a clear expression of project complexity. The implementation includes risks of conflict of interest and collaboration issues since more than 35 people from four organisations are involved. While the external consulting company is responsible for change management at BYGST, the IWMS provider and developer are focused on delivering the appropriate IT solution for the customer, whose organisation and needs for the IWMS in the meantime might be changing. To exemplify, during the implementation, BYGST has changed the CEO twice, and two of the interviewees deeply involved in IWMS implementation are no longer employed at BYGST (Head of IT department and IT senior consultant). Moreover, BYGST has, as mentioned in section 3.1 and 4.1, recently also got responsibility for providing FM services to their tenants, which means that the implementation now also must relate to the development of a new business area. To support this organisational change, BYGST has subsequently decided to implement the IWMS FM module in the near future. This integration of FM and REM in centralised services supports earlier findings by van der Schaaf (2002).These organisational changes clearly demonstrate that the IWMS provider during the implementation needs close collaboration and continuous input from the customer to ensure proper system configuration that matches the actual needs of the organisation. On the other hand, the IWMS customer, besides financial costs, must be prepared to invest time and human resources in the implementation process to get the desired solution. The implementation must include goal setting and user involvement, and be able to manage organisational changes, as highlighted in Gibler et al. (2010). This might particularly be a challenge for smaller REM organisations with limited resources, and partially explain, why mainly larger REM organisations decide to implement IWMS. 


\section{Conclusion}

An Integrated Workplace Management System (IWMS) is a technological platform that combines relational data records for the building stakeholders (employees, managers, tenants, suppliers etc.), assets (built assets, furniture, equipment) and business process (workflows) to deliver a deeper insight on real estate management across the entire organisation. The strength of IWMS is that its modules rely on a common database which contains essential information on the building stakeholders and assets, so the entire organisation uses the same data foundation in diverse business processes.

An IWMS is mainly implemented in larger real estate organisations that are used to work in silos and use multiple IT systems to manage their real estates. While earlier research has shown that global CREM organisations mainly implemented IWMS with focus on cost reductions, our study indicates that PREM organisations can have other drivers for implementing IWMS. Drivers for implementing IWMS in this study were identified as quality improvements of business processes with the aim of establishing more knowledge-based organisation. The main drivers observed, in order of priority, are: data standardisation, validation and exchange; faster execution of business processes; time savings and resource optimisation; better interoperability between departments; and savings on IT costs.

An IWMS can be configured to match the needs of a REM organisation, but the system has also certain limitations. Our study has disclosed that BYGST's requirements on environmental sustainability were not sufficiently covered by IWMS features and that the system needed to be supported further by an EMS solution. However, the implemented EMS solution, that later will be interfacing with IWMS, already delivers more standardised energy consumption data, time savings and faster execution of business processes related to energy management.

The IWMS implementation is a complex process involving many different stakeholders inside and outside of an organisation and can take several years to complete. The IWMS implementation should not be perceived as a definite IT implementation project, but as the organisational change process involving different stakeholders across the entire organisation. The successful rollout of IWMS is therefore conditioned by several prerequisites such as availability of internal resources and their competences during the implementation process, stepwise strategic implementation, and clear definitions of which business processes the new system must support.

A point of discussion for further research might be management of environmental sustainability through IT systems. Moreover, there is a need for further research on the relationship between IT systems in use and the portfolio size, and how more recent IT solutions and technological developments like IoT and Big Data modelling can enhance REM.

\section{References}

Bygningsstyrelsen (2012) The Danish Building and Property Agency - the preferred choice for customers and the state.

Bygningsstyrelsen (2015) Projektinitieringsdokument (PID).

Bygningsstyrelsen (2017) What does the Danish Building and Property Agency do? Available at: https://www.bygst.dk/english/about-us/ (Accessed: 16 February 2018).

Dewulf, G., Krumm, P. and de Jonge, H. (2000) Successful corporate real estate strategies. 
Nieuwegein: Arko Publishers, 2000.

DFM Network and Basico (2017) FM-systemer i Danmark - et overblik.

Ebbesen, P. (2015) 'Information Technology in Facilities Management - A Literature Review’, in EuroFM Research Papers.

Ebbesen, P. and Bonke, S. (2014) 'Identifying Concepts for Studying Implementation of Information Technology in Facilities Management', CIB Facilities Management Conference, pp. $1-13$.

Gartner (2017) Market Guide for Integrated Workplace Management Systems.

Gibler, K. M., Gibler, R. R. and Anderson, D. (2010) 'Evaluating corporate real estate management decision support software solutions’, Journal of Corporate Real Estate, 12(2), pp. 117-134. doi: 10.1108/14630011011049559.

Hanley, B. P. and Brake, D. J. (2016) 'Putting asset data at the heart of organisational decisionmaking using an Integrated Workplace Management System’, in Asset Management Conference, pp. 1-7.

Jensen, P. A. and van der Voordt, T. (2017) Facilities Management and Corporate Real Estate Management as Value Drivers: How to Manage and Measure Adding Value. Oxfordshire: Routledge.

Madritsch, T. and May, M. (2009) 'Successful IT implementation in facility management', Facilities, 27(11/12), pp. 429-444. doi: 10.1108/02632770910980727.

Anonymous (2018) - conference paper. Reference anonymised for review.

Sandquist, N. J. (2015) The Top Ten Resons You Should be Implementing IWMS in 2015. Trimble.

Schafer, R. (2014) 'Magic Quadrant for Integrated Workplace Management Systems’, Gartner, Inc., (June).

Short, T. (2017) What is IWMS? Available at: https://www.softwareadvice.com/resources/what-isiwms-software/ (Accessed: 12 July 2018).

Van der Schaaf, P. (2002) 'Public real estate management challenges for governments', doctoral thesis, Delft University Press, p. 259.

Van der Voordt, T. (2017) 'Facilities Management and Corporate Real Estate Management: FM/CREM or FREM?’, Journal of Facilities Management, 15(3), pp. 244-261.

Yin, R. K. (2014) Case Study Research. 5th edn. SAGE Publications. 